\title{
Squandering Carbon Must Lead to Economic Failure
}

\author{
Stefan Petters',2, Kalvin Tse ${ }^{2}$, Yong Cao1, Klaus Mauthner ${ }^{3}$ \\ ${ }^{1}$ BoD of guo-Business Development Consult Vienna, Austria \& Bestrong International Ltd., Hong Kong, China \\ ${ }^{2}$ R\&D Bestrong International Ltd., Hong Kong, China \\ ${ }^{3}$ BoD of Katyusha Technologies Services, Vienna, Austria \\ Email: go@int88.biz
}

Received 12 April 2016; accepted 13 May 2016; published 16 May 2016

Copyright (C) 2016 by authors and Scientific Research Publishing Inc.

This work is licensed under the Creative Commons Attribution International License (CC BY).

http://creativecommons.org/licenses/by/4.0/

cC) (i) Open Access

\section{Abstract}

In a world that consumes resources faster than our nature can reproduce them we need to adopt more and more re-use practices-particularly urgent for contemporary Carbon. Using Fossils is an import of pre-historic Carbon into present age and we keep doing it because end of lifecycle carbonaceous resources are either used for energy recovery only, or dumped to rot. In any case, Carbon is disposed into Atmospheric Carbon Stock. Carbohydrates contain carbon [C], hydrogen [H], and oxygen [0], mostly in a ratio of $\mathrm{C}_{n} \mathrm{H}_{2 n} \mathrm{O}_{n}$ and store bio-energy and genetic information controlling the flow of chemical energy through metabolism. Hydrocarbons on the other hand are chemical compounds that consist only of the elements carbon and hydrogen. Both are formed by a carbon skeleton having hydrogen atoms attached to that backbone. At $2 \mathrm{H}_{2}: 1 \mathrm{C}$ ratio $55 \%$ stored chemical energy stems from Hydrogen and $45 \%$ from the Carbon. If burned for energy recovery, the Hydrogen content forms water vapor, but its Carbon carrier discards $\mathrm{CO}_{2}$ into atmosphere as if it was a one-way pack. Why not Capture Carbon physically for new Hydrocarbon Synthesis' Use prior to direct electrochemical Energy Recovery from Hydrogen rather than today's three step Power generation (-heat-mechanical power motion energy-electricity-). For example for bottom-up Ethylene Synthesis physically Captured Carbon replaces 2 ltr crude oil per kg ethylene output. At a similar Energy Yield, only reduced by the $\mathrm{CO}_{2}$ transformation losses of the Carbon Capture process, the Captured Carbon can be additionally used as a resource at arms' length market prices, adding to Cost-effectiveness and making the Energy more economic at an increased Environmental Performance due to increased Carbon Efficiency.

\section{Keywords}

Ambient Resources, Atmospheric Carbon Stock, Carbohydrates, Carbon Capture, Carbon Efficiency, Carbon-Neutrality, Hydrocarbons, Hydrogen, Ethylene Synthesis 


\section{Introduction}

Energy Economics may have been looking at Resource Pricing and peak-energy Output per Input yields, but, even until today, rarely focusing on Carbon Efficiency. Notwithstanding ambient Carbon inventory movements being the most relevant indicators for Environmental Quality! Global Carbon distribution nowadays is $\sim 42,000$ $\mathrm{Gt} / \mathrm{C}$ in oceans and lakes, 10\% thereof in known Fossil Reserves followed by $3000 \mathrm{Gt} / \mathrm{C}$ in the top soil of land, slightly more than 6 times the Carbon stored in life vegetation and biosphere including us humans. The only Carbon stock discussed recently is the Carbon Dioxide $\left[\mathrm{CO}_{2}\right]$ in the atmosphere, having reached 2 times the level of a balanced metabolism in the order of $10 \%$ of Carbon kept in earth. So we say, we have $400 \mathrm{Gt} / \mathrm{C}$ too much Carbon in the atmosphere-representing just about $1 \%$ of maritime Carbon stock! If that decreased by venting $1 \%$ into atmosphere we will have exhausted the remaining tolerance for $2^{\circ} \mathrm{C}$ Climate Change Carbon Budget!

\section{Use of Hydrocarbons and Carbohydrates}

\subsection{Oil Refineries}

Crude Oil usually comes at a content of $83 \%_{\mathrm{wt}}$ Carbon [C] and $12 \%_{\mathrm{wt}}$ Hydrogen [H]. This translates into an atomic C:H ratio of 1:1.73 (Nonbaking Coal in comparison has about 1:0.53, while Natural Gas has 1:4). Looking at atomic $\mathrm{C}: \mathrm{H}$ ratio of Octane $\left(\mathrm{C}_{8} \mathrm{H}_{18}\right)$ as a major representative for gasoline refined from crude oil, we find 26\% increase of Hydrogen content to 1:2.25 also called platforming Hydrocarbons. Additional Hydrogen needed for hydrogenation is produced onsite by splitting water over Carbon via so called steam reforming, liberating $\mathrm{H}_{2}$ under formation of Carbon monoxide [CO]. By subsequent water gas shift reaction the $\mathrm{CO}$ can split a further water molecule $\left[\mathrm{H}_{2} \mathrm{O}\right]$ into a second $\mathrm{H}_{2}$ under formation of $\mathrm{CO}_{2}$ being squandered into atmosphere today.

There are talks about Carbon Capture for Sequestration [CCS] for Climate Change mitigation. But that adds cost to Hydrogen production and unless directly usable as pump gas at oil or gas wells leaves ambiguities about long term retention security. Alternatives to mineralize by accelerated weathering of abundant magnesium silicate rocks delivering Silica as a product used in glass production or sand casting as well as hydroscopic applications. Per tonne of $\mathrm{CO}_{2} \sim 1.6$ tonnes Peridotite are needed costing more than the achievable revenues of $\sim \mathrm{U} \$ 70$.

\subsection{Global Hydrogen Production}

$\sim 48$ Mega tons [Mt] of Hydrogen representing 96\% of annual volume are produced by steam reforming, generating $0.44 \mathrm{Gt} \mathrm{CO}_{2}$. This is the compounded Carbon Emissions from contemporary feedstock composition being $50 \%$ Natural Gas, 31\% Crude Oil and 19\% Coal, totally consuming 1.25\% of world fossil primary energy supply consuming 266.4 million $\mathrm{m}^{3}$ water. Average Energy Efficiency of this Hydrogen production is 86\% [1].

Further 4\% are produced by electrolysis of water at an Energy Efficiency of 55.5\% (underlying electricity hypothetically at $100 \%$ ) consuming 18 million $\mathrm{m}^{3}$ water. In most cases the Hydrogen is used with adjacent flue gas $\mathrm{CO}_{2}$ to synthesize Methane as energy storage yield from volatile New Renewable Electricity excess productions [2]. In a way this can be seen as a single loop Carbon Recycling approach, evidencing Carbon Efficiency to prevail over Energy Efficiency. However such Synthetic Natural Gas [SNG] costs 100 times current market price—or over 600 times current European Carbon Exchange [ECX] rate per metric ton of $\mathrm{CO}_{2}$ [3].

The biggest show-stopper for Carbon Efficiency improvement by a Hydrogen Mobility implementation is the awkwardness of Hydrogen in storage and transportation. There is hope that decentralization of onsite Hydrogen production will create a big enough market for sufficient cost-down roadmaps of electrolysis investment costs [4].

\subsection{Fuel based Electricity Generation}

Today thermoelectric plants take the pain of 3 consecutive transformation steps:

fuel $->$ heat | heat $->$ motionl power | motion power -> electricity.

The heavier the fuel, the less adaptive is the first step to load fluctuations generating $\mathrm{CO}_{2}$ by combustion of carbonaceous fuel. As carbonaceous fuel burning always means disposal of the Carbon backbone carrying the Hydrogen atoms of Hydrocarbons as if it were a one-way pack, idling operation of steps 2 and 3 burden overall Carbon Efficiency substantially [5].

New Renewable Energies' volatility in combination with grid regimes providing off-take privileges actually 
completely miss the $\mathrm{CO}_{2}$ Emission mitigation objectives when their back-up supply must be secured by solid or heavy fuel thermal power plants. While consumers are forced to pay premium prices for so called "Green" Electricity, the conventional infrastructure can just squander the Carbon of theoretically saved fuel in idling mode.

Unfortunately Carbon Trade and Renewable Energy Subsidy Schemes have misled several markets to increase the use of biomass as so called "Carbon Neutral” (solid) fuel for Secondary Energy Recovery. Apart from the cost situation in need of imposing all uncovered overruns on the consumers, Carbon Efficiency is poorest among all fuel options. Nevertheless large industries with high needs of process heat take advantage of waste management regime specific cost socialization schemes originally implemented to finance incinerators called Waste to Energy. So the public ends up paying large part of their energy cost for offered co-incineration capacities at cheap or even costly terms of allocating the so called Secondary Resources on longer term contracts. The public is deceived by holding such practices out to be "Zero Waste" concepts—as if Carbon squandered into the atmosphere was no waste? Although even most advanced incineration technologies have a $20 \%$ higher emission rate per energy unit recovered than a coal power plant would have-unnecessary to mention that in comparison to Natural Gas there is a factor 2 under load and indefinite for idling mode. Therefore no biomass combustion or waste incineration should be seen Carbon Neutral because it definitively is not Carbon Efficient [6]!

\section{Carbon Efficiency}

After almost two decades Energy Efficiency focus Carbon Efficiency came up as a new issue rather recently only. The authors actually picked it up at the first Asian IAEE Conference in China [7]. Very little was heard about it during COP21, although the 12.12.2015 Climate Protection Accord would urgently call for its assessment throughout the 195 signatory countries' usage practices of carbonaceous fuels [8].

This paper only deals with the energy related Carbon Efficiency aspects. But as mentioned in the introduction above, land-use and soil management practices' Carbon Efficiency have an even bigger impact on climate change than just the Energy sector or fragments of it, for example transportation. The nexus of agricultural Carbon Efficiency and Energy is fatally whitewashed by broadly contemplated Carbon-Neutrality hypothesis having enticed solid or refined liquid biofuel programs grossly violating against Carbon Efficiency principles across multiple levels [9]. Climate does not care where Carbon comes from, as long as more Carbon stored in matter is turned into Atmospheric Stock than marine, soil and biosphere's metabolism can assimilate contemporarily.

\subsection{Uplifting Carbon Efficiency with State of the Art Technologies}

As discussed under sec. 2.2 above, the production of Hydrogen from any Hydrocarbon primary energy carrier as well as the synthesis of Hydrogen with $\mathrm{CO}_{2}$ into SNG can be viewed State of the Art. If we just took the average Carbon Efficiency of today's fuel mix in Hydrogen production Carbon Footprint of utility scale Hydrogen Fuel Cell [HFC] electricity generation would be $0.45 \mathrm{t} / \mathrm{MWh}_{\mathrm{el}}$ under load ( $50 \%$ of current value). In idling mode either SNG or Methanol could be synthesized from abundant Hydrogen and part of the $\mathrm{CO}_{2}$ creating easier to store fossil substitute commodities for storage and use in existing infrastructures.

Cost wise however such electricity supply might cost 2.5 times today's electricity wholesale market price and the SNG's lack of competitiveness against LNG was already mentioned in sec.2.2. Therefore it becomes necessary to create higher additional value from the Carbon squandered in today's practices.

The authors happen to formerly come from a business built on special material solution developments. Therein they industrialized thermo-catalytic dissociation [TCD] of Hydrocarbon gases by Chemical Vapor Deposition [CVD] from synthetic diamond to a continuous ${ }_{\text {nano }}$ Carbon and Hydrogen co-production from Methane $\rightarrow>$ a physical Carbon Capture for Use [10].

\subsection{Physical Carbon Capture for Re-Use [CCU]}

Dry Methane splitting had been demonstrated in the Kvaerner Process but was considered inadequate from the operating temperature regime required. Introduction of catalysts alike used in Steam Methane Reforming [SMR] reaction temperatures could be lowered to similar orders of magnitude like SMR's. Efforts to lower catalyst usage enticed application of catalyst carrier materials with high specific surface resulting in nano-crystalline structures of the Carbon deposited on it [11].

Due to the high electron mobility in ${ }_{\text {nano }}$ Carbon, reaction temperatures could be further lowered by activation 
of electrons via microwave exposure, paving the way for a so called cold wall reactor [12]. However, original

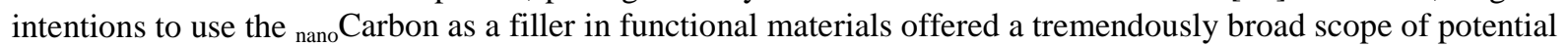
applications requiring specific tailoring for each niche. Therefore nanoCarbon is regarded a rather exotic expensive type of material. In lack of any predictable time to market for ${ }_{n \text { nano }}$ Carbon use in materials' mass application, refinery scale Hydrogen production by CCU via TCD had been awed so far.

To avoid tedious qualification procedures and FDA approval for nanoCarbon material applications over the entire lifecycle, TCD was not yet implemented industrially on full scale. However, as TCD is proven feasible and effective on smaller scale to valorize decomposition gas from organic residues, the authors modelled recycling of catalyst by cannibalizing the nanoCarbon through the available decomposition $\mathrm{CO}_{2}$ under moderate temperature combined with microwave exposure. The Carbon monoxide yield thereof in combination with the upstream co-produced Hydrogen led to a synthesis gas platform. Via Water Gas Shift [WGS] reaction of parts of the Carbon monoxide the $\mathrm{H}_{2}$ :CO ratio can be tailored to the need of any downstream Chemical Synthesis.

At arms' length market price for Hydrogen at U\$ 2.02 per kg biogas could be valorized $~ 0.21 \mathrm{U} \$$ per $\mathrm{m}^{3}$ (at a $\mathrm{CH}_{4}: \mathrm{CO}_{2}$ ratio of 60:40). Carbon Emission for the Hydrogen from such use of biogas would be $12.3 \mathrm{~kg} \mathrm{CO}_{2}$ per kg Hydrogen ( 92.5\% of a biogas SMR). In case of a Fischer Tropsch Paraffin Oil Synthesis $96 \%$ of Carbon in the biogas could be recycled valorizing it $\sim 0.18 \mathrm{U} \$$ per $\mathrm{m}^{3}$ (assuming a market price of $0.53 \mathrm{U} \$$ per liter blend).

Unfortunately European subsidies compete at U\$ 0.38 per $\mathrm{m}^{3}$ ( $€ 0.16$ per $\mathrm{kWh}_{\mathrm{el}}$ Feed-In Tariff equivalent). But a Methanol Synthesis sold at $\sim 0.53$ U\$ per liter could alternatively valorize biogas at even $\sim 0.54$ U\$ per $\mathrm{m}^{3}$. With regard on Carbon Efficiency the CCU HFC-Utility Supply would improve by $20 \%$ (-60\% current value).

\section{3. nanoCarbon Use as Precursor for Plastics}

Due to the slump in crude oil prices causing ambiguities about going forward fuel pricing the authors developed a novel usage path based on a Calcium Oxide catalyst carrier system for the ${ }_{\text {nano Carbon Capture allowing to form }}$ Calcium Carbide as precursor for Acetylene production. Since the deposited Carbon can be stored safe and transported it can be back-end processed independently from the Hydrogen production tied to the hydrocarbon or carbohydrate decomposition process. Although Calcium Carbide melting is a pretty energy intensive process, it can be arranged in a separate batch process and therefore use abundant renewable energy whenever available. This can be either New Renewable Electricity, like applied for Hydrogen electrolysis, or heliostat heat [13].

Since the Calcium Carbide melting generates Carbon Monoxide from one third of the available Carbon a WGS reaction may provide Hydrogen for a hydrogenation of Acetylene derived from hydrolysis of the Calcium Carbide. Ethylene nowadays trading at $\sim 0.98 \mathrm{U} \$$ per kg would allow a biogas valorization at $\sim 0.49 \mathrm{U} \$$ per $\mathrm{m}^{3}$ and enable to reintroduce $\sim 70 \%$ of the Carbon stored in the decomposition gas into the cycle of matter. Since such recycled Carbon could stay stored in material over 3 - 5 product lifecycles along the recycling cascade, this usage path option delivers the best Carbon Efficiency. Particularly if waste treatment at the end of life-cycle would employ Carbon Recycling as well. Each kg Ethylene derived from CCU can substitute 2.1 liters of crude oil, what is competitive even against subsidized Feed-In Tariff regimes.

\subsection{Value of Carbon (See Table 1)}

ECX currently quotes the metric ton $\mathrm{CO}_{2}$ at $€ 4.78$ which would be equal to $19.63 \mathrm{U} \$$ per metric ton pure Carbon. Exxon-Mobil contemplated Carbon Capture cost through Sequestration at $85 \mathrm{U} \$$ per ton Carbon (equal $\sim 23.20 \mathrm{U} \$$ per ton $\mathrm{CO}_{2}$ ). On the other hand, purified liquid $\mathrm{CO}_{2}$ is contracted at $65 \mathrm{U} \$$ per ton amounting to 238.33 U\$ per ton captured Carbon [14].

Physically Captured Carbon for Use actually ranges from mineralization applications starting 110 - 560 U\$ through refining from 300 - 1200 U\$ up to Carbon Use in Composites from 1500 - 8000 U\$ per tonne CCU.

\section{Conclusions}

\subsection{Power Generation with CCU, While Keeping Current Fuel Mix}

$33 \%$ of contemporary world fossil primary energy demand goes into $66 \%$ of today's global electric power generation at a fuel mix of $30 \%$ Natural Gas, $10 \%$ Oil and $60 \%$ coal [15]. 90\% of electricity produced from NG could also be provided from a HFC powered with Hydrogen from CCU by TCD. Gasification of coal for power 
Table 1. Value Adding from CCU.

\begin{tabular}{|c|c|c|c|c|c|}
\hline \multicolumn{6}{|c|}{ Examples of Carbon Use and ist Value at arms' length market prices } \\
\hline Sequestration & Exxon CCS & ETX & cement foamer & $0.5 \%$ terra preta & \\
\hline U\$ per tonne & -85.00 & -1.46 & 112.00 & 560.00 & \\
\hline Refining & liquid $\mathrm{CO}_{2}$ & FiT Paraffin & $\mathrm{CH}_{3} \mathrm{OH}$ & $\mathrm{CaC}_{2}$ (Carbon) & $\mathrm{Na}_{2} \mathrm{CO}_{3}$ (Carb.) \\
\hline U\$ per tonne & 238.33 & 334.87 & 1098.93 & 1173.33 & 1766.48 \\
\hline Composites & nat.Graphite & filter Carbon & Carbon Black & Li-I Bat.Carb. & 3D print ink \\
\hline U\$ per tonne & 1500.00 & 1680.00 & 2909.00 & 5000.00 & 8000.00 \\
\hline
\end{tabular}

generation at an $850^{\circ} \mathrm{C}$ temperature regime with a partial SMR and TCD post treatment of Methane fractions, rebounding from equilibrium reactions, a load adaptability can be provided. While the coal continuously produces Hydrogen, its use can be switched between HFC power generation and Methane Synthesis during idling operation. In such idling mode CCU can be maximized by backfeeding all TCD Hydrogen into additional Methane Synthesis. Assuming a 40\% idling and 60\% load operation Carbon Efficiency from coal fuel can be improved by greater $50 \%$ at equal electricity output.

For the oil fuel fractions we assume conventional Steam Reforming to Hydrogen, delivering 150\% electricity by HFC, better than direct combustion can. On average an overall Carbon Capture for Use ratio of 38\% can be achieved.

Assuming an average added value of 500 U\$ per metric ton of Captured Carbon Used for refining substitutes of crude oil derived commodities sold at arms’ length prices, the existing fuel mix could yield an extra U\$ 48.5 per $\mathrm{MWh}_{\mathrm{el}}$. This saves $\sim 135 \%$ worth a barrel of crude oil per $\mathrm{MWh}_{\mathrm{el}}$ by the substitute Carbon Captured for Use.

Further the avoided Carbon Emission could get an ECX award of $16.5 \mathrm{US}$ per $\mathrm{MWh}_{\mathrm{el}}$. At current market prices this would in total mean an extra revenue of U\$ 121 per $\mathrm{MWh}_{\mathrm{el}}$ generated.

\subsection{Electricity from NG or SNG Only}

If all electricity was generated electrochemically from Hydrogen produced by CCU via TCD of NG (or SNG), Carbon turnover could be reduced by factor 2.6. This could save $~ 50 \%$ current fuel cost. About $57 \%$ of Carbon input could be Captured for economic Use.

Assuming further growing Renewable Electricity in the grids available abundant excess energy at low load periods will increase. With Substitute Natural Gas Synthesis from Steam Reformed Captured Carbon during previous high load phases supplied from Fuel Cell Electricity fed by TCD-Hydrogen from NG or SNG, such Carbon could contribute 60\% of the new SNG's Energy content at 20\% auxiliary energy input to drive Steam Reforming. The required doubling of Hydrogen availability for the consumption of all associated Steam Reforming $\mathrm{CO}_{2}$ in a SNG Synthesis could be delivered by electrolysis off additional excess electricity. This Use of Captured Carbon as an Energy storage in combination with New Renewable excess electricity could therefore provide SNG at an output efficiency for the auxiliary input energy of $>75 \%$.

At a $10 \%$ Carbon loss to $\mathrm{CO}_{2}$ per transformation cycle the storage energy efficiency would still reach an order of $70 \%$ reducing $\mathrm{CO}_{2}$ emissions from fossil Hydrogen Fuel Cell electricity to 13\% or 6.5\% of today.

\subsection{Carbon Fortune Organic Waste}

What our civilization throws away and/or leaves just rotting by itself represents 2900 Mtoe a year. After return of 55\% of its Carbon content to composting the remaining Carbon available for CCU can be made available as a crude oil substitute at a Carbon Efficiency of 79\%. Not using this Fortune means throwing away U\$ 80 - 600 per tonne of squandered Carbon! Why burn under socialized uncovered cost overruns, rather than refining at arms’ length profits?

\section{Acknowledgements}

Thanks to WWF's support the authors, by which we have been inspired to found Carbotopia ${ }^{\mathrm{TM}}$ standing for an Innovation Implementation initiative for CCU application from Waste Valorization. Carbotopia ${ }^{\mathrm{TM}}$ further ac- 
knowledges its FDI-financing model to UN-Secretary General of Rio20+ - his Excellency Sha Zukang’s terms \& conditions cited for building Eco-Civilization in Emerging and Developing parts of the World, advocating for their chance to not have to follow the Western paradigm of polluting first for cleaning up later: "Our planet might not give us the time to clean up, once the $60 \%$ world population within the One and Road regions owning $23 \%$ of GDP today will economically double or triple on the basis of past or current practices of squandering Carbon on the expense of civilization" [16].

\section{References}

[1] Hans Geerlings: Sustainable Hydrogen. Shell Global Solutions TU-Delft, October 2009. https://www.tue.nl/fileadmin/content/onderzoek/Eindhoven_Energy_Institute_EEI/EnergyDays/Serie_1_2008_2010/20 $\underline{\text { 09_10_08/Geerlings.pdf }}$

[2] Hermann Pengg: E-Fuels_-Potential Future Propellant. Presentation $\mathrm{CO}_{2}$ as a Resource, Linz, 27 November 2012.

[3] Bloomberg Business: Energy Markets. Crude Oil \& Natural Gas, Refined Products, Emissions, 23 March 2016. http://www.bloomberg.com/energy

[4] Ernst Fleischhacker, FenSustain Systems; Green Corridor of EU: Hydrogen and Fuel-Cells. Technology Forum Alpbach in Tyrol, 28 August 2015.

[5] Passerini, G. (2014) University Politecnica delle Marche; “Environmental Impact”; Wessex Waste Management Coference 2014, Ancona, May 2014.

[6] Petters, S., Tse, K. and Mauthner, K. (2015) Posterpresentation European Bimass Conference \& Exhibition. Hybridizing Ambient Carbon Stock Refining with Power to Gas, Vienna, June 2015.

[7] Zhang, G.B. (2014) Specialist Committee for National Energy Commission \& former Minister of National Energy Administration. New Requirements to Energy Researchers (Opening Remarks), 4th Asian and 1st China IAEE Conference, Beijing, August 2014.

[8] Petters, S. (2016) TechTalk Presentation at World Future Energy Summit, Refining Trash by Unravelling Carbon for Re-Use, WFES2016, Jan 2016.

[9] Günal, H., Korucu, T., Birkas, M., Özgöz, E. and Halbac-Cotoara-Zamfir, R. (2015) Threats to Sustainability of Soil Functions in Central and Southeast Europe. Sustainability, 7, 2161-2188. http://www.mdpi.com/2071-1050/7/2/2161/htm

[10] Mauthner, K. and Hammel, E. (2001) CCVD Process for Tubular Carbon Nano-Fiber Fabrication. Patent AT 373732 ; Priority March 2001, AT.

[11] Hammel, E., Mauthner, K. and Brichta, W. (2007) Nanotechnology as a Useful Contribution to the Reduction of Carbon Dioxide Emissions. Presentation, Lebnitz Institute, November 2007. http://leibniz-institut.de/archiv/hammel 27 11 07.pdf

[12] Mauthner, K., Tang, X.H. and Haubner, R. (1999) Method of Producing a Nanotube Layer on a Substrate; Patent US20020102353 A1, Priority September 1999, AT.

[13] Mauthner, K., Tse, K. and Petters, S. (2012) Method and System for Acetylene $\left(\mathrm{C}_{2} \mathrm{H}_{2}\right)$ or Ethylene $\left(\mathrm{C}_{2} \mathrm{H}_{4}\right)$ Production. Patent EP 14195574.0. Filing December 2012.

[14] Environmental Expert Report; NewGens for Hydrogen Technology Waste to Energy Plant Description. http://www.environmental-expert.com/companies/newgens-31970/

[15] US Energy Information Administration. http://www.eia.gov/tools/faqs/faq.cfm?id=667\&t=8

[16] Sha, Z.K. (2015) Global Trade Cooperation and the China Policies. Key Note. 2015 GBO-China Global Green Technology Cooperation Conference, Beijing, November 2015. 